\title{
NOVEDADES EN CASEARIA (FLACOURTIACEAE) PARA ARGENTINA
}

\author{
HÉCTOR A. KELLER ${ }^{1}$, FABIAN E. GATTI² \& JUSTO HERRERA ${ }^{2}$
}

\begin{abstract}
Summary: Keller H.A., F. E. Gatti \& J. Herrera. 2009. Novelties in Casearia (Flacourtiaceae) for Argentina. Bonplandia 18(1): 13-17. ISSN: 0524-0476.

Casearia obliqua Spreng. (Flacourtiaceae) is recorded for the first time to Argentina, based on specimens collected beside Iguazú river, in Misiones province. The taxon is here described and illustrated. The presence of Casearia gossypiosperma Briq. in Misiones, a tree mentioned in 1936 for that province, is here documented by mean herbarium material. A key for identifying the argentinean species is included.
\end{abstract}

Key words: Casearia obliqua, Casearia gossypiosperma, Misiones Province, new records

Resumen: Keller H.A., F. E. Gatti \& J. Herrera. 2009. Novedades en Casearia (Flacourtiaceae) para Argentina. Bonplandia 18(1): 13-17. ISSN: 0524-0476.

Se cita por primera vez para la flora de Argentina, Casearia obliqua Spreng. (Flacourtiaceae), sobre la base de ejemplares recolectados junto al río Iguazú, en la provincia de Misiones. Este taxón es descripto e ilustrado. Se certifica mediante material de herbario la presencia en Misiones de Casearia gossypiosperma Briq., especie arbórea que fue mencionada para dicha provincia en 1936. Se incluye una clave para determinar las especies de Casearia de Argentina.

Palabras clave: Casearia obliqua, Casearia gossypiosperma, Misiones, nuevas citas.

\section{Introducción}

El género Casearia Jacq. cuenta con aproximadamente 180 especies, que se distribuyen en las regiones tropicales del mundo (Sleumer, 1980). Para la Argentina se han mencionado 5 especies: C. aculeata Jacq., $C$. decandra Jacq., C. gossypiosperma Briq., $C$. sylvestris Sw. y C. lasiophylla Eichler (Zuloaga \& Morrone, 1999; Keller \& Tressens, 2007), tres de ellas, C. decandra, $C$. sylvestris y $C$. lasiophylla, han sido documen- tadas para la provincia de Misiones (Keller \& Tressens, 2007). Casearia gossypiosperma ha sido mencionada para Misiones (Devoto \& Rothkugel, 1936) en un listado de plantas donde no se especifican ejemplares de herbario.

Recientes campañas de recolección efectuadas en el margen sur del río Iguazú, al este de las cataratas, han permitido hallar ejemplares de Casearia obliqua Spreng. (Flacourtiaceae), especie arbórea que hasta ahora había sido considerada endémica de Brasil. En el presente trabajo se cita por pri-

1 Instituto de Botánica del Nordeste, Casilla de Correo 209, 3400 Corrientes, Argentina. E-mail: hkeller@facfor.unam.edu.ar

${ }^{2}$ Centro de Investigaciones Ecológicas Subtropicales. Parque Nacional Iguazú, Misiones, Argentina 
mera vez dicho taxón para la flora de Argentina. Por otra parte, el material de herbario de Casearia gossypiosperma, recolectado recientemente en la localidad de Puerto Iguazú, permite certificar su presencia en Misiones.

\section{Casearia obliqua Spreng.}

Fig. 1

Sprengel, C.P.J., Syst. Veg. 2: 355. 1825.

Árbol hasta 15 m de altura con copa piramidal y fuste cilíndrico hasta $25 \mathrm{~cm}$ de diámetro. Corteza escamosa, escamas grisáceas rectangulares. Ramificación monopodial, con ramas primarias dispuestas en estratos; ramitas zigzagueantes, dísticas, conspicuamente lenticeladas, cuando jóvenes pardo-rojizas y pubescentes, con pelos largos y cortos, tornándose pardo-oscuras a grisáceas, puberulentas a glabrescentes cuando adultas. Hojas simples, persistentes, estipuladas; estípulas subuladas, pubescentes, prontamente caedizas hasta 4,8 mm long. x $1 \mathrm{~mm}$ lat.; pecíolo pubescente, acanalado, $6-12 \mathrm{~mm}$ long x 0,7-0,8 mm diám.; lámina de 2,3-6,7 cm long. $x$ 1,4-2,8 cm lat., elíptica, ovada a ovado-oblonga, oblicua, subtriplinervia, notablemente pelúcido rayada. Inflorescencia fasciculada sésil o con pedúnculo hasta 1,5 $\mathrm{mm}$, con 20-70 flores; brácteas escariosas, escuamiformes, pardo rojizas, puberulentas, ca. $1 \mathrm{~mm}$ long. Pedicelos articulados 1-2,5 $\mathrm{mm}$ de la base, blancos o verdosos por debajo de la articulación y blancos o rosados por encima de la misma, pubescentes; bractéolas cuculadas ca. $1 \mathrm{~mm}$ long. x 0,5 $\mathrm{mm}$ lat., pardo rojizas. Tépalos 5, blancos a rosados, ovado-suborbiculares, puberulentos, 1-1,5 mm long. Estambres 10, ca. 1,5 $\mathrm{mm}$ long., anteras diminutas, eglandulares. Lóbulos del disco espatulados, pilosos, mucho menores que la longitud del estambre. Ovario subtrígono, estilete 3-fido; estigmas capitados, reflexos. Fruto cápsula elipsoidea, 6- angular, hasta $5 \mathrm{~mm}$ long., dehiscencia 3-valvar. Semillas redondeadas a oblon- go-elipsoides, testa foveolada, pilosa; arilo fibroso con indumento velloso.

Nombres vulgares: En Brasil recibe los siguientes nombres: Cafezeiro do mato, guaçatumba preta, estalador, estralador, estraladeira, espeteiro, guaçatumba vermelha, cambroé, (Klein \& Sleumer, 1984), erva-delagarto; folha-miúda; canela-de-veado; paude-espeto (Marquete \& Vaz, 2007).

Distribución geográfica: Brasil, en los Estados de Bahia, Espírito Santo, Minas Gerais, Pernambuco, Paraná, Rio de Janeiro, Rio Grande do Sul, Santa Catarina y São Paulo (Longhi et al., 2006; Marquete \& Vaz, 2007, En Argentina hasta el presente sólo hallada en un área restringida, en el margen sur del río Iguazú, provincia de Misiones.

Observaciones ecológicas: Es una especie heliófila, que crece en el interior de selva densa, donde alcanza el dosel; en áreas abiertas se torna más baja; también crece en sucesiones secundarias y afloramientos rocosos (Marquete \& Vaz, 2007). En el Estado de Paraná, se la mencionó como un elemento característico de la selva marginal del río Iguazú (Pasdiora, 2003). En Argentina, forma parte de la flora marginal del río Iguazú.

Fenología: En Brasil se menciona su floración para los meses de octubre a junio y la fructificación durante el verano (Marquete \& Vaz, 2007). En Argentina fue hallada con botones florales en el mes de octubre, con flores y frutos inmaduros a principios de noviembre.

Usos: Al igual que sus congéneres, el árbol cuenta con caracteres de valor ornamental, entre ellos el fuste recto, la copa piramidal dispuesta en estratos, alta producción de flores blancas o rosadas, en glomérulos densos y vistosos. Tiene importancia para la apicultura. Se la menciona como planta medicinal contra mordeduras de serpientes, también ha sido usada para tratar molestias en la piel durante la lepra incipiente (Klein \& Sleumer, 1984). 

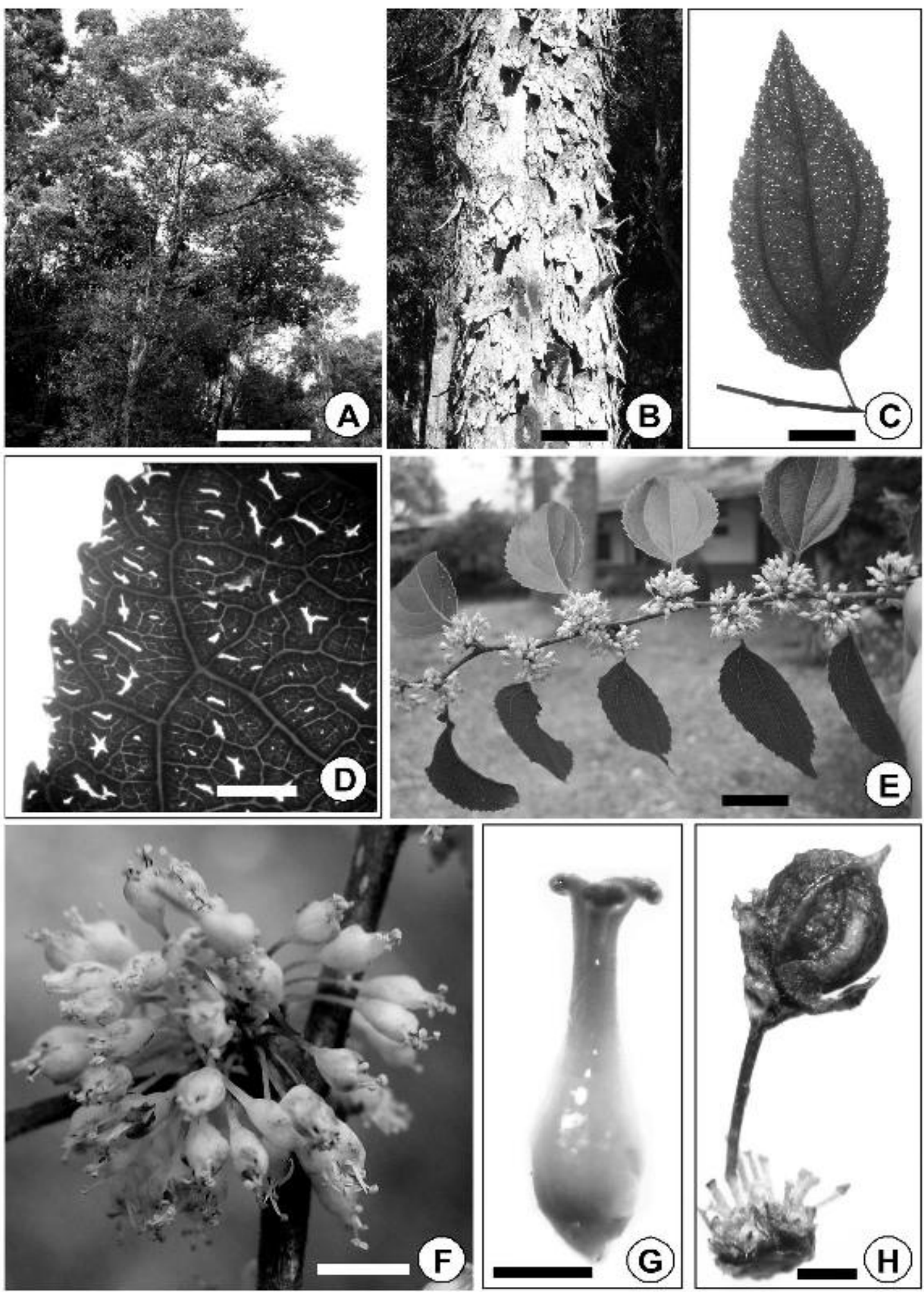

Fig. 1: A: ejemplar. B: corteza escamosa. C: hoja. D: detalle de las rayas traslúcidas de la lámina. E: rama florífera. F: glomérulo. G: ovario con estilo trífido. H: fruto inmaduro. Escalas: A: 2 m; B: $10 \mathrm{~cm}$; C: $1 \mathrm{~cm}$; D: 0,2 cm; E: 1 cm; F: 0,3 cm; G y H: 0,1 cm. A-H, Gatti \& Herrera 37 (Fotos de F. E. Gatti). 
Material examinado: ARGENTINA. Misiones. Dep. Iguazú. Parque Nacional Iguazú, margen del río Iguazú, al oeste del arroyo Irene, 23X-2007, Herrera \& Gatti s/n (CTES); al este de acceso a Garganta del Diablo, 25 42 ' 11,1» S $54^{\circ}$ 25' 34» W, 23-IX-2008, Keller \& Gatti 6133 (CTES); 03-XI-2008, Gatti \& Herrera 37 (CTES), 11-XI-2008, Keller \& Gatti 6442 (CTES).

\section{Casearia gossypiosperma Briq.}

Esta especie ha sido citada para Brasil, Perú, Bolivia, Paraguay, Argentina y Uruguay (Klein \& Sleumer, 1984), en nuestro país ha sido documentada para la provincia de Formosa (Sleumer, 1980) y ha sido registrada en una lista de árboles, arbustos, palmas y lianas del Territorio de Misiones
(Devoto \& Rothkugel, 1936), pero en dicho manuscrito no se especifica la localidad exacta ni se cita material testigo.

Se han recolectado ejemplares de herbario de Casearia gossypiosperma en la localidad de Puerto Iguazú, en un área periurbana con remanentes de selva. También se ha observado un ejemplar de gran tamaño (ca. 30 m) dentro del Parque Nacional Iguazú, donde junto con otras especies arbóreas emergentes, ocupa el estrato superior de la selva.

Nombres vulgares: mbavy, catiguá oby (Argentina), cambroé (Brasil).

Material examinado: ARGENTINA. Misiones. Dep. Iguazú. Cercanías de la ciudad de Puerto Iguazú. 25 36' 20,4" S - 54 33' 51,2" W, 19-V2009, Keller \& Gatti 7048 (CTES).

\section{Clave para identificar las especies de Casearia de la Argentina}

A. Estambres 8. Arbustos apoyantes o erectos, generalmente espinosos

C. aculeata Jacq.

A’. Estambres 10. Árboles y arbustos inermes

B. Estilos indivisos

C. Tépalos de 5 a 6 mm long., hojas tomentosas, ramas floríferas áfilas

C. lasiophylla Eichler

C’. Tépalos de 3-4,5 mm long., hojas glabras, raro pubescentes en el hipofilo, ramas floríferas foliosas

C. decandra Jacq.

B'. Estilos trífidos

D. Ramas floríferas áfilas; fascículos axilares de 8-12 flores, largamente pedunculados que surgen de un receptáculo leñoso formado por la concrescencia de brácteas exteriores persistentes y escariosas

C. gossypiosperma Briq.

D’. Ramas floríferas foliosas, glomérulos axilares plurifloros, sésiles o cortamente pedunculados. Receptáculo leñoso ausente.

E. Lámina foliar oblonga, pinnatinervada, de 6-14 cm long.; pecíolo de 0,3-0,8 cm long.

C. sylvestris Sw.

E’. Lámina foliar elíptica, ovada, raro ovado-oblonga, subtriplinervia, de 2,3-6,7 cm long.; pecíolo de 0,6-1,2 cm long.

C. obliqua Spreng. 


\section{Bibliografía}

DEVOTO, F. E. \& M. ROTHKUGEL. 1936. Informe sobre los bosques del Parque Nacional del Iguazú. Extracto del Boletín del Ministerio de Agricultura de la Nación 37 (1-4): 1-99.

KELLER H. A. \& S. G. TRESSENS. 2007. Presencia en argentina de dos especies de uso múltiple: Acca sellowiana (Myrtaceae) y Casearia lasiophylla (Flacourtiaceae). Darwiniana 45(2): 204-212.

KLEIN, R. M. \& H. O. SLEUMER. 1984. Flacourtiáceas en R. Reitz (ed.). Fl. Ilustr. Catarinense, FLAC: 1-96. 8 fig. y 11 mapas.

LONGHI, S. J., D. A. BRENA, J. F. GOMES, I. DA SILVA NARVAES, G. BERGER \& A. J. SOLIGO. 2006. Classificação e caracterização de estágios sucessionais em remanescentes de floresta ombrófila mista na flora de São Francisco de Paula, RS, Brasil. Ciência Florestal 16(2): 113-125.

MARQUETE, R. \& A. M. S. F. VAZ. 2007. O gênero Casearia no estado do Rio de Janeiro, Brasil. Rodriguésia 58 (4): 705-738.

PASDIORA, A. L. 2003. Florística e fitossociologia de um trecho de floresta ripária em dois compartimentos ambientais do Rio Iguaçu, Paraná, Brasil. Tesis de Maestría en Ciencias Forestales. Universidad Nacional do Parana. Curitiba, 59 pp.

SLEUMER, H. O. 1980. Flacourtiaceae. Flora Neotropica Monograph 22: 1-499.

ZULOAGA, F. \& O. MORRONE. 1999. Catálogo de las Plantas Vasculares de la República Argentina II. Dycotiledoneae. Fabaceae - Zygophyllaceae. Monogr. Syst. Bot. Missouri Bot. Gard. 74: 6231269.

Original recibido el 13 de noviembre de 2008; aceptado el 27 de mayo de 2009. 
BONPLANDIA 18(1). 2009 